\title{
Discussion on the Network Teaching
}

\author{
Lehui Huang $^{1,}$, Miaomiao $\mathrm{Li}^{2, \mathrm{~b}}$ \\ ${ }^{1}$ Education School, Jiangxi Science \& Technology Normal University, Nanchang, China \\ ${ }^{2}$ Education School, Jiangxi Science \& Technology Normal University, Nanchang, China \\ aHLH8899@163.com; 'biMiaomiao0710@163.com
}

Keywords: network teaching; characteristic; advantage; disadvantage

\begin{abstract}
Along with the arrival of twenty-first century, information technology develops very rapidly, and computer technology has gradually penetrated into the modern life, especially the application in college teaching. The lash produced by the network teaching to traditional teaching mode and students' learning plays good role in promoting teaching; therefore, the paper describes the characteristics, advantages and disadvantages of network teaching.
\end{abstract}

\section{Introduction}

Network teaching is that teachers transfer teaching information to students through computer network technology, and students get the information through the network. That is to say, due to many characteristics of network teaching, how the teachers play the leading role and stimulate students to learn autonomously according to different teaching patterns of network teaching, needs to understand the online teaching mode, characteristics, problems and solutions, and implement continuously in teaching work.

\section{Characteristics of network teaching}

The sharing of the resources. Network resources can be shared among the countries in the world, and any users can recognize the whole world through the network. Knowledge is the common wealth of mankind, and the ladder of development and progress of human society, which should be shared by the people through a variety of means at the maximum rang and extent. Ways and means of information transmission over the past can not achieve the common dream of human perfectly. The application of modern network technology make us understand other countries' politics, economy, culture, science and technology, sports, religion and other aspects, at the same time, the situation of our country can also be recognized and understood through peoples' queries. So it realizes that the intellectuals stay inside while they know everything outside in the true sense. Through the network, learning the history of China and other countries in the world has unique advantage.

Timeliness. In the knowledge economy and information age, people focus on the timeliness of the information. The timeliness of the network refers to that any information will be received by all network uses in a timely manner once the information is released on the network. It is not limited by time and space, and can be transferred very fast through graphic and other media in all-round and three-dimension. Its timeliness surpasses far any other kinds of information and is the most effective way of information dissemination. In order to reform education, develop education and cultivate new talents in line with the world trend, the most critical issue is whether the new teaching philosophy, teaching techniques and teaching contents can be disseminated to educators and educates in a fast and efficient way.

Interactivity. Interactivity refers to two-way transmission of network information transmission. That is to say that, any users can be the receivers of information, and also be releasers and disseminators of information. The network mainly exchanges information through e-mail, bulletin boards and online chat system. Good teaching activities must rely on two-way communication between teachers and students. Network environment not only makes the exchange between 
teachers and students more smoothly, but also eliminates the face-to-face fear and shyness, which makes discussion carry out in a relaxed atmosphere. The interactivity of network makes teaching efficiency high and teaching effect better.

Individualized learning. Individualized learning means that learners can choose learning contents and progress according to individual needs and levels when carrying out network learning. Online education allows students to obtain various courses and materials more conveniently, and individual network learning is more realistic and superior than individual learning based on a single computer. It not only inherits all the features of computer, but also can use massive information sources of network to provide students with more updated information. In addition, it can also take advantage of dynamic nature of the network to modify and improve the original design in a timely manner, so as to better meet the needs of learners. For teachers, they can adjust teaching schedule according to students' individual difference and cognitive level, and make specific response through the analysis and judgment of students' learning. High degree of flexibility and choice makes individualized, personalized learning realized really. As Bill Gates said in "the road ahead", people in any place can have best courses.

\section{Advantages of network teaching}

Sociality. Network teaching has the sociality. It makes the learning contents of universities and schools into broad society, and its educational objects are unrestricted, which greatly increases the learning opportunities of social groups. The learning process, learning resources and teaching management are open to the community, and the learning process, learning methods and learning time can be decided by learners according to their specific circumstances. Online teaching is not restricted by school walls and national boundaries, and learners can enter the online classroom, obtain rich and shared learning resources at home, school and other places connecting with the internet. Students failing college entrance examination have the study opportunities in excellent universities; students in ordinary junior and senior high schools have the opportunity to listen to lectures of teachers in key schools; through online training, in-service personnel have the opportunity to study self-taught in their spare time, so that the limited educational resources radiate to more people and regions, and get rid of stringent requirement of the learning time and place of traditional teaching. Learners can arrange their learning time and learning progress flexibly according to their needs through asynchronous system, VOD video on demand system and other modes whenever and wherever, and also can share educational resources and teachers' guidance by relying on teaching information retrieval system or public multimedia communication network.

Quickness. In network multimedia teaching, teachers can use QQ, MSN, e-mail, BBS, voice mail and other media technology to achieve fast-style teaching. Synchronous or asynchronous communication between students and teachers and among students becomes a breeze. Through e-mail, students can obtain personalized learning guidance and help from teachers easily. Through QQ, MSN and other tools, students in different places can easily realize instant communication across time and space, share learning experiences, discuss or resolve difficulties and problems encountered in learning, so as to cultivate spirit of mutual cooperation between them and enhance mutual understanding and friendship.

Richness. Richness refers to teaching resources. The main carrier of traditional teaching content is textbook, while the main carrier of network teaching content is the network. Large-capacity multimedia courseware and network information provided by the network greatly enrich the learning resources. The information expressed by multimedia not only has perceived value, but also has aesthetic value. Online information adopts digital processing, and the characteristic of digital information is not only easy to copy and modify, but also easy to create aesthetic context with strong infection by using hypertext link manner. These contents, like feelings, gradually form the aesthetic imagery and aesthetic experience, so the entire learning activities have strong emotional color and become important learning experience of students' emotional development. At the same time, on one hand, network teaching makes learners share teaching resources of different countries or log into other educational sites to obtain information needed, to enrich the teaching content and 
broaden their horizons; on the other hand, it allows learners to dynamic integrated information with illustration, audio-visual, which changes the inherent learning modes of learners.

\section{Disadvantages of network teaching}

The problem of classroom capacity---the rational use of network resources. In order to increase classroom capacity, the officer place a lot of information resources on the network, but it produces a serious consequence. That is: rich resources make students dazzling, background information, electronic blackboard, pictures, links information......students have no time to browse, let alone take notes, analyze, think, absorb, synthesis and digest, resulting in that students are unable to start and read randomly. It actually makes network teaching under the situation out of control. So increasing the capacity of information should not be as the goal of network teaching, and improving teaching efficiency is the goal. As teachers, they must handle well with the relationship between teachers and teaching materials. While using them to teach, they must analyze carefully, study in-depth, clear the teaching objectives, highlight the theme, focus and difficulty, and can not follow their bent for students' interests. Therefore, only use network resources rationally, can they master classroom capacity and improve the teaching efficiency.

The problem of autonomous learning-repositioning teachers' role. In order to facilitate students' learning, teachers reduce teaching time while increasing the independent reading time of students without interference. What kind of role do the teachers act in the network teaching? Whether teachers interfere when students read independently? Whether it will affect students' independent study? These are problems in the practice of network teaching. In the process of network teaching, teachers should transform from the role of imparting knowledge to the role of facilitators, helpers and organizers of students' meaning construction. Therefore, teachers' role in network teaching needs to reposition.

The problem of emotional interaction-necessary complement of traditional means. Another tricky problem encountered in practice is how to solve the problem of emotional interaction in network teaching. How to demonstrate the function of ideological education under the network environment? For example, playing audio and video materials at the beginning of class, interspersing vivid narrating in class, and carrying out fierce ideological battle among students at the end of class, can play the role of emotional interaction. Therefore, in order to solve the problem of emotional interaction under the network environment, the traditional methods can do necessary complement.

The problem of courseware commonality-optimal design of courseware templates. Under normal circumstance, courseware is basically designed for a specific lesson, so the versatility is poor. The versatility is the most important criteria of investigating the efficiency and effectiveness of courseware. If the versatility of courseware is very strong, the teacher who designs it can use it , and the whole school and country can also use it.

The requirement of network teaching to the equipment and technology is very high and difficult to promote-step by step, clear division of labor. Network teaching has certain requirement to the equipment; the school can not carry out network teaching activities without certain number of computers and internet access. However, the development of our understanding of network teaching inevitably goes through a progress, and new learning way can not be achieved overnight change. This change is a process from quantitative change to qualitative change. We can use very low cost to build small practice environment to explore the network teaching. Of course, with the deepening of practice and the development of social economy, the physical conditional of the network teaching will be improved.

\section{Conclusion}

In short, the network teaching is only a way of teaching, and can't become the all education. No matter how developed the network technology is, it still needs teachers' correct guidance. In order to converse the knowledge to students, teachers must stand in the forefront of teaching and continue 
to improve the teaching quality. Only in this way, can they adapt the ability of teaching by information technology in the new era.

\section{References}

[1]Shenghua Yang. Discussion on the advantages and development of network education[J]. Chinese distance education, 2002(12).

[2]Shangwei Tan. Quality assurance and evaluation of distance learning courses[J]. Chinese distance education, 2002(12)

[3]Gangshan Fu, Hongliang Ma. The network distance education[J]. Science press, 2007.

[4]Wenyan Tan. The application of example teaching in computer teaching[J]. Journal of Zhuhai education college, 2003(3).

[5]Zhiting Zhu, Lu Wang. The application of network education[J]..Beijing normal university press, 2004.

[6]Jun Xiao. The construction of online teaching resource support service system[J]. Chinese distance education, 2003(5). 